\title{
A novel glycosylated Cu/Zn-containing superoxide dismutase: production and potential therapeutic effect
}

\author{
Maria Angelova, ${ }^{1}$ Pavlina Dolashka-Angelova, ${ }^{2}$ Emilia Ivanova, ${ }^{1}$ \\ Julia Serkedjieva, ${ }^{1}$ Ludmila Slokoska, ${ }^{1}$ Svetlana Pashova, ${ }^{1}$ \\ Reneta Toshkova, ${ }^{3}$ Spassen Vassilev, ${ }^{1}$ Ivan Simeonov, ${ }^{1}$ \\ Hans-Jürgen Hartmann, ${ }^{4}$ Stanka Stoeva, ${ }^{5}$ Ulrich Weser ${ }^{4}$ \\ and Wolfgang Voelter ${ }^{5}$
}

Author for correspondence: Wolfgang Voelter. Tel: +49707 12973041. Fax: +49707 1293361 e-mail: wolfgang.voelter@uni-tuebingen.de

1 Institute of Microbiology, Bulgarian Academy of Sciences, 26 Academician G. Bonchev, 1113 Sofia, Bulgaria

2 Institute of Organic Chemistry, Bulgarian Academy of Sciences, 9 Academician G. Bonchev, 1113 Sofia, Bulgaria

3 Institute of Experimental Pathology and Parasitology, Bulgarian Academy of Sciences, 23 Academician G. Bonchev, 1113 Sofia, Bulgaria

4 Anorganische Biochemie, Physiologisch-chemisches Institut der Universität, Tübingen, Hoppe-SeylerStraße 4, D-72076,

Tübingen, Germany

5 Abteilung für Physikalische Biochemie des Physiologisch-chemischen Instituts der Universität, Tübingen, Hoppe-SeylerStraße 4, D-72076,

Tübingen, Germany
The fungal strain Humicola lutea 103 produces a naturally glycosylated Cu/Zn SOD. To improve its yield, the effect of an increased concentration of dissolved oxygen (DO) on growth and enzyme biosynthesis by the producer, cultivated in a 3 I bioreactor, was examined. Exposure to a $20 \%$ DO level caused a 1.7-fold increase of SOD activity compared to the DO-uncontrolled culture. Maximum enzyme productivity of SOD was approximately $300 \times 10^{3} \mathrm{U}$ (kg wet biomass) ${ }^{-1}$. The novel enzyme was purified to electrophoretic homogeneity. The presence of $\mathrm{Cu}$ and $\mathrm{Zn}$ were confirmed by atomic absorption spectrometry. The molecular mass of $H$. lutea Cu/Zn SOD was calculated to be $31870 \mathrm{Da}$ for the whole molecule and $15936 \mathrm{Da}$ for the structural subunits. The $\mathbf{N}$-terminal sequence revealed a high degree of structural homology with Cu/Zn SOD from other prokaryotic and eukaryotic sources. $H$. lutea Cu/Zn SOD was used in an in vivo model for the demonstration of its protective effect against myeloid Graffi tumour in hamsters. Comparative studies revealed that the enzyme (i) elongated the latent time for tumour appearance, (ii) inhibited tumour growth in the early stage of tumour progression (73-75\% at day 10 ) and (iii) increased the mean survival time of Graffi-tumour-bearing hamsters. Moreover, the fungal Cu/Zn SOD exhibited a strong protective effect on experimental influenza virus infection in mice. The survival rate increased markedly, the time of survival rose by $5.2 \mathrm{~d}$ and the protective index reached $86 \%$. The $H$. Iutea SOD protected mice from mortality more efficiently compared to the selective antiviral drug ribavirin and to commercial bovine SOD. In conclusion, our results suggest that appropriate use of the novel fungal SOD, applied as such or in combination with selective inhibitors, could outline a promising strategy for the treatment of myeloid Graffi tumour and influenza virus infection.

Keywords: protein sequencing, myeloid Graffi tumour, influenza infection, protective effect

\section{INTRODUCTION}

Superoxide dismutases (SODs, EC 1.15.1.1) are metalloenzymes involved in the physiological response

Abbreviations: DO, dissolved oxygen; MST, mean survival time; SOD, superoxide dismutase; $\mathrm{TBH}$, tumour-bearing hamsters. to oxygen toxicity by their ability to catalyse the dismutation of the superoxide anion $\left({ }^{\circ} \mathrm{O}_{2}^{-}\right)$to molecular oxygen and $\mathrm{H}_{2} \mathrm{O}_{2}$ (Fridovich, 1995). Three classes of SODs have been reported, based on their active site metals: $\mathrm{Cu} / \mathrm{Zn} \mathrm{SOD}, \mathrm{Fe}$ SOD and Mn SOD (Fridovich, 1995). At present, there is evidence that Ni SOD occurs in prokaryotes as well (Matès \& Sánchez-Jimenez, 
1999). The recent interest in this enzyme is determined by its important physiological role in primary cellular antioxidant defence and its potential therapeutic use. Numerous elucidations of structures and functions of SOD from prokaryotes and eukaryotes contribute to the understanding of the molecular evolution of this enzyme family and the therapeutic application of SOD as an antioxidant. Considerable experimental evidence has been accumulated that the use of SOD might be beneficial in the treatment of postischaemic reperfusion injury (Rios et al., 1999), rheumatoid and osteoarthritis (Kakimoto et al., 1993), brain trauma (Yunoki et al., 1997) and influenza-induced lung pneumonitis (Sidwell et al., 1996). SODs have been proposed to be clinically useful for a wide variety of applications, including prevention of oncogenesis, tumour promotion, tumour invasiveness (Matès \& Sánchez-Jiménez, 2000) and reduction of the cytotoxic and cardiotoxic effects of anticancer drugs (Trotti, 1997; Sabitha \& Shyamaladevi, 1999).

The large scientific and practical interest in SODs has resulted in intensive developments of new technologies for enzyme production from various sources, including animal and human erythrocytes, plants and microorganisms. Filamentous fungi are especially suitable for SOD production because of their potential advantages, i.e. rich abundant mycelium, intensive respiration and high level of cyanide-resistant respiration (Sakajo et al., 1993). Microbial technology would also be more effective and inexpensive compared to the production of this enzyme from bovine erythrocytes. Moreover, despite great efforts, efficient production of recombinant human SOD in prokaryotic systems or simple eukaryotes has failed. This lack of success has greatly complicated large-scale production and genetic engineering of the protein (Stenlund \& Tibell, 1999).

To improve the in vivo pharmacological activity of SOD, the enzyme has been conjugated with mono- and polysaccharides (Fujita et al., 1992), haemoglobin (D'Agnillo \& Chang, 1998) and lecithin (Nakauchi et al., 1996), etc. A major advantage of such modified SODs is their longer half life in plasma and blood (Maksimenko et al., 1993). Our preliminary investigations have shown that the fungal strain Humicola lutea 103 mainly produces the $\mathrm{Cu} / \mathrm{Zn}$ enzyme. Moreover, $H$. lutea SOD is a naturally glycosylated enzyme (unpublished data) which could be isolated in very few other cases. The secretory tetrameric extracellular mammalian SOD is the only glycosylated SOD, besides the H. lutea enzyme, described so far (Edlund et al., 1992). Glycoenzymes of this kind do not need additional processing for conjugation and modification as do nonglycosylated enzymes.

Here, we present the conditions for the production of a novel, naturally glycosylated $\mathrm{Cu} / \mathrm{Zn}$ SOD from the fungal strain $H$. lutea 103 . We report also on the characterization of the purified enzyme, as well as on its protective effect in experimental influenza virus infection and on myeloid Graffi tumour.

\section{METHODS}

Micro-organism. The fungal strain, Humicola lutea 103, from the Mycological Collection of the Institute of Microbiology, Sofia, was used throughout and maintained at $4{ }^{\circ} \mathrm{C}$ on beer agar, pH 6.3.

Cultivation, equipment and conditions. Cultivation was performed in a 31 bioreactor, ABR-09, developed and constructed by the former Central Laboratory for Bioinstrumentation and Automatisation (CLBA) of the Bulgarian Academy of Sciences. The bioreactor was equipped with $\mathrm{pH}$ and automatic dissolved oxygen (DO) monitoring equipment and a control system.

The composition of the culture medium has been described previously (Angelova et al., 1996). For the inoculum, $80 \mathrm{ml}$ seed medium was inoculated with $5 \mathrm{ml}$ spore suspension at a concentration of $2 \times 10^{8}$ spores $\mathrm{ml}^{-1}$ in $500 \mathrm{ml}$ Erlenmeyer flasks. The cultivation was performed on a shaker (220 r.p.m.) at $30^{\circ} \mathrm{C}$ for $24 \mathrm{~h}$. For bioreactor cultures, $160 \mathrm{ml}$ of the seed culture was brought into the 3 l bioreactor, containing $1850 \mathrm{ml}$ of the production medium. The cultures were grown at $30^{\circ} \mathrm{C}$ for $120 \mathrm{~h}$. The fermentation parameters under DO-uncontrolled conditions were: impeller speed, 600 r.p.m.; air flow, 1 v.v.m. [1 vol. air $(1 \mathrm{vol} \text {. liquid })^{-1}(\mathrm{~min})^{-1}$ ]. In this case, only the changes in DO level during fermentation were measured. For the DO-controlled culture system, aeration and impeller speed were regulated in such a way as to produce $20 \%$ oxygen saturation in the liquid. The results obtained in this investigation were evaluated from experiments repeated using three or five parallel runs.

Analytical methods. The cell-free extract was prepared as described previously (Angelova et al., 1995). SOD activity was measured by the nitro blue tetrazolium (NBT) reduction method of Beauchamp \& Fridovich (1971). One unit of SOD activity was defined as the amount of SOD required for inhibition of the reduction of NBT by $50 \%\left(A_{560}\right)$ and was expressed as $U$ (mg protein $)^{-1}$. Cyanide $(2 \mathrm{mM})$ was used to distinguish between the cyanide-sensitive isoenzyme $\mathrm{Cu} / \mathrm{Zn}$ SOD and the cyanide-resistant Mn SOD. Cu/Zn SOD activity was obtained as total activity minus the activity in the presence of $2 \mathrm{mM}$ cyanide. Protein was estimated by the Lowry procedure, using crystalline bovine albumin as standard. Soluble reducing sugars were determined by the SomogyiNelson method (Somogyi, 1952). Dry weight determination was performed on samples of mycelia harvested throughout the culture period. The culture fluid was filtered through a Whatman (Clifton, USA) no. 4 filter. The separated mycelia were washed twice with distilled water and dried to a constant weight at $105^{\circ} \mathrm{C}$.

Purification of $\boldsymbol{H}$. Iutea Cu/Zn SOD. The frozen mycelium was partially thawed and then suspended in 4 vols $25 \mathrm{mM}$ potassium phosphate buffer, $\mathrm{pH} 7 \cdot 8$, containing $1 \mathrm{mM}$ PMSF. The suspended material was disrupted by an Ultra-TurraxIKA-Werk homogenizer. Cell debris was removed by filtration through a Buchner funnel and the mixture was clarified by centrifugation at $13000 \mathrm{~g}$ for $20 \mathrm{~min}$ at $4^{\circ} \mathrm{C}$. All subsequent steps were performed at $4^{\circ} \mathrm{C}$. The supernatant was concentrated approximately three times by membrane ultrafiltration (Amicon PM-10). The concentrated crude extract was further fractionated using acetone, chilled to $-20^{\circ} \mathrm{C}$. Cooled acetone was slowly added to the culture filtrates to a concentration of 0.4 vols with vigorous stirring for $30 \mathrm{~min}$. The mixture was incubated for $2 \mathrm{~h}$ at $-20{ }^{\circ} \mathrm{C}$ and the precipitate was collected, centrifuged at $13000 \mathrm{~g}$ for $20 \mathrm{~min}$ and discarded, while the supernatant was treated with $1 \cdot 1$ vols of chilled acetone. The 
mixture was held for $12 \mathrm{~h}$ at $-20{ }^{\circ} \mathrm{C}$; then the precipitate was collected by centrifugation ( $13000 \mathrm{~g}$ for $20 \mathrm{~min}$ ) and suspended in distilled $\mathrm{H}_{2} \mathrm{O}$. The clear viscous supernatant was loaded on a Sephadex G-75 column $(2 \times 50 \mathrm{~cm}$; Pharmacia), previously equilibrated with $50 \mathrm{mM}$ potassium phosphate buffer, $\mathrm{pH} 7 \cdot 8$, and the column was eluted with the same buffer.

Further purification was achieved by ion exchange chromatography on a DEAE cellulose- 52 column $(3.5 \times 10 \mathrm{~cm}$; Serva), equilibrated in $50 \mathrm{mM} \mathrm{KH} \mathrm{PO}_{4}$ buffer, $\mathrm{pH} 7 \cdot 8$. The $\mathrm{Cu} / \mathrm{Zn}$ SOD was eluted with an $\mathrm{NaCl}$ gradient $(0-0 \cdot 1 \mathrm{M})$. The active fractions were loaded for additional purification onto an FPLC system, equipped with a 10/10 Mono Q anion exchange column. The column was previously equilibrated with $50 \mathrm{mM}$ potassium phosphate buffer, $\mathrm{pH} 7 \cdot 8$, and the elution was effected employing stepwise increases in $\mathrm{NaCl}(0-0 \cdot 1 \mathrm{M})$. Fractions with $3100 \mathrm{U}$ (mg protein $)^{-1}$ were further purified and desalted on a Nucleosil RP C18 column $(250 \times 10 \mathrm{~mm}$; Macherey-Nagel) to allow determination of the N-terminal sequence and amino acid composition. The conditions used for HPLC separation were as follows: eluant A, 0.058\% trifluoroacetic acid (TFA); eluant B, $80 \%$ acetonitrile in A. The gradient was run from 5 to $100 \% \mathrm{~B}$ within $60 \mathrm{~min}$ at a

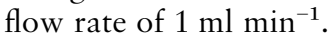

Characterization of $\boldsymbol{H}$. lutea $\mathbf{C u} / \mathbf{Z n}$ SOD. Flameless atomic absorption spectroscopy of $\mathrm{Cu}, \mathrm{Zn}$ and $\mathrm{Mn}$ was performed on a Perkin-Elmer $400 \mathrm{~S}$ spectrometer, equipped with a HGA 76B graphite furnace.

Purity control of the enzyme and measurement of molecular mass were performed on $10 \%$ polyacrylamide gels, as described by Laemmli (1970), and the gels, stained for protein detection, were compared with duplicate gels stained for SOD activity as described by Misra \& Fridovich, (1977). The following molecular mass standards were used: trypsinogen (24 kDa), egg albumin (45 kDa), bovine albumin (66 kDa) and Limulus polyphemus haemocyanin (monomer, $70 \mathrm{kDa}$ ).

$\mathrm{N}$-terminal amino acid sequence analysis was performed using an Applied Biosystems sequencer, model 473A.

Mass spectra were obtained by matrix-assisted laser desorption ionization MS (MALDI 1-MS) (Kratos, MALDI III equipment; Shimadzu). The sample (10 pmol) was dissolved in $0.1 \%(\mathrm{v} / \mathrm{v})$ TFA and applied onto the target. Analysis was carried out in $\alpha$-cyano-4-hydroxycinnamic acid. Solutions of chicken egg ovalbumin $(44400 \mathrm{kDa})$ and bovine serum albumin $(66430 \mathrm{Da})$ were used to calibrate the molecular mass scale.

The protein was analysed for carbohydrates with the orcinol/ $\mathrm{H}_{2} \mathrm{SO}_{4}$ test (Francois et al., 1962).

Experiments concerning the effect of $H$. lutea SOD on myeloid Graffi tumour. The protective effect was examined by the following parameters: mean latent time (d) for tumour appearance; mean survival time (MST, d), estimated at day 45 after tumour transplantation; and inhibition (\%) of tumour growth, estimated according to Toshkova (1995)

Inhibition $(\%)=$

diameter of tumours of control hamsters

diameter of tumours of H. lutea SOD-treated hamsters $\times 100$

Experimental animals. Forty, 2-month-old Golden Siberian hamsters of both sexes, weighing 80 to $100 \mathrm{~g}$, were used for the experiments. For the examination of the SOD-protective effect, the animals were separated into four experimental groups.

Group 1. Animals were treated intraperitoneally (i.p.) with a $65 \mathrm{U} H$. lutea SOD single dose per animal, twice a week, 1 week before and 2 weeks after tumour transplantation.

Group 2. Animals were treated with a $65 \mathrm{U}$ H. lutea SOD single dose per animal, twice a week, 2 weeks after tumour transplantation, starting on the day of transplantation.

Group 3. Animals were treated with a $125 \mathrm{U}$ H. lutea SOD single dose per animal, twice a week, 2 weeks after tumour transplantation, starting on the day of transplantation.

Group 4. Control animals with tumours without treatment.

Tumour. The myeloid tumour was induced by the mouse Graffi virus, adapted for hamsters by Yakimov et al. (1979). The tumour was maintained in vivo by subcutaneous (s.c.) inoculation of $2 \times 10^{4}$ viable cells in the interscapular region. The tumour was $100 \%$ transplantable and $100 \%$ lethal for hamsters (Yakimov et al., 1979; Toshkova, 1995).

Experiments concerning the effect of $\boldsymbol{H}$. lutea SOD in experimental influenza infection. Male and female inbred ICR mice (16-18 g) were obtained from the Experimental Animal Station of the Bulgarian Academy of Sciences in Slivnitza, Sofia, Bulgaria. They were quarantined $24 \mathrm{~h}$ prior to use and maintained under standard laboratory conditions with tap water ad libitum for the duration of the studies. The experimental groups were of 10 animals each. At the end of the experiments, surviving mice were sacrificed by cervical dislocation.

Virus infection. In mice, the infection was induced under ether anaesthesia by intranasal inoculation of A/Aichi/2/68 $(\mathrm{H} 3 \mathrm{~N} 2)$, adapted to the mouse lung. This virus causes haemorrhagic pneumonia in mice. The strain was from the collection of the Institute of Microbiology, Bulgarian Academy of Sciences, Sofia, Bulgaria. To cause lethal infection, mice were infected by passages in the lungs with $5-10 \mathrm{LD}_{50}$ of the virus in a $0.05 \mathrm{ml}$ volume of physiological saline per mouse.

Experimental design. Mice were treated with $H$. lutea $\mathrm{Cu} / \mathrm{Zn}$ SOD (500 $\mathrm{U}$ per mouse $\mathrm{d}^{-1}$ ) in $0.1 \mathrm{ml}$ saline administered intravenously (i.v.) 4-7 d after virus exposure and were observed for death daily for $21 \mathrm{~d}$. All experiments were done in parallel with the selective antiviral drug ribavirin (SigmaAldrich) and SOD from bovine erytrocytes (Sigma-Aldrich). Ribavirin was inoculated i.p. in a dose of $125 \mathrm{mg}$ per mouse $\mathrm{d}^{-1}$; bovine SOD was inoculated i.v. in a dose of $500 \mathrm{U}$ per mouse $\mathrm{d}^{-1}$.

The protective effect was estimated by the increase in the rate of survival $(\%)$, protective index (PI, \%) and prolongation of MST (d) as described by Serkedjieva \& Ivanova (1997). PI was determined from the equation $(\mathrm{PR}-1) / \mathrm{PR} \times 100$, where $\mathrm{PR}$ (protective ratio) is $M_{\text {control }} / M_{\text {experiment }}(\mathrm{M}$ is mortality).

The results are the mean values from three or four independent experiments. Reduction of mortality rates compared to placebo controls were evaluated using $\chi^{2}$ analysis. Student's $t$-test was employed to analyse differences in survival times. Standard deviations were determined within $95 \%$ confidence intervals.

Ethical aspects. Experiments with animals are inevitable and indispensable in investigations concerning the treatment of influenza infection and tumour growth. Only in this way could a matter-of-fact characterization of the protective effect of $H$. lutea SOD be obtained. That is why the experiments with 
animals cannot be replaced by experiments with tissue culture cell lines. The number of experimental animals was reduced as much as possible, depending on statistical significance. The animals were sacrificed using ether narcosis and cervical dislocation to minimize the amount of suffering. Refinement of the tests with animals was achieved by careful planning of multifactor experiments.

The animals were bred under standard conditions, accepted by the Bulgarian Veterinary Health Service. Specialized personnel took care of the welfare of the animals. In implementing this study we have adhered most strictly to all national and international ethical provisions applicable to Bulgaria where the investigations with experimental animals were carried out.

\section{RESULTS AND DISCUSSION}

\section{Effect of DO concentration on Cu/Zn SOD production}

It is well known that SOD expression is markedly enhanced by augmenting intracellular production of $\cdot \mathrm{O}_{2}^{-}$under conditions of increased levels of DO in the
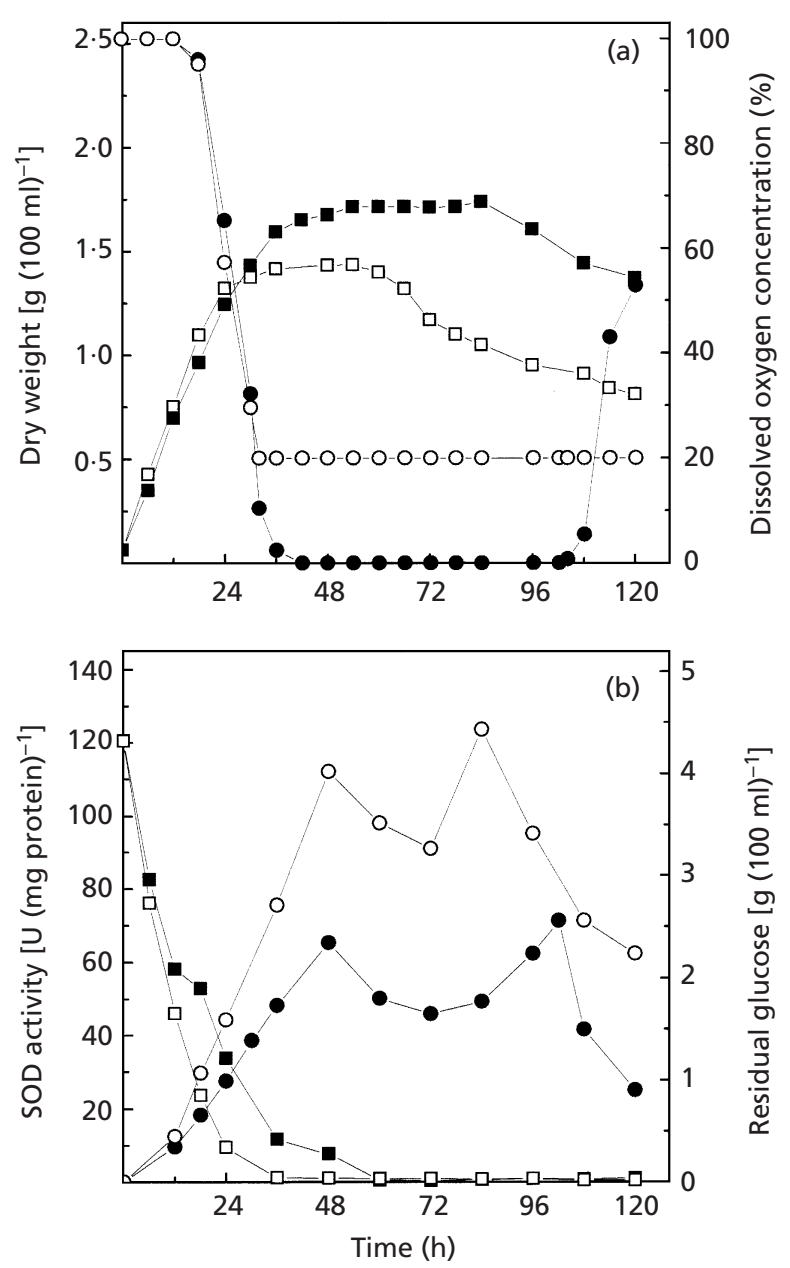

Fig. 1. Time courses of (a) mycelia growth $(\boldsymbol{\square}, \square)$ and dissolved oxygen concentration $(0, O)$, and (b) SOD production $(0, \bigcirc)$ and glucose consumption ( $\square, \square$ ) in $\mathrm{H}$. lutea 103 culture, grown under DO-uncontrolled $(\boldsymbol{\square}, \mathbf{Q})$ and $20 \%$ DO-controlled $(\square, \bigcirc)$ conditions.

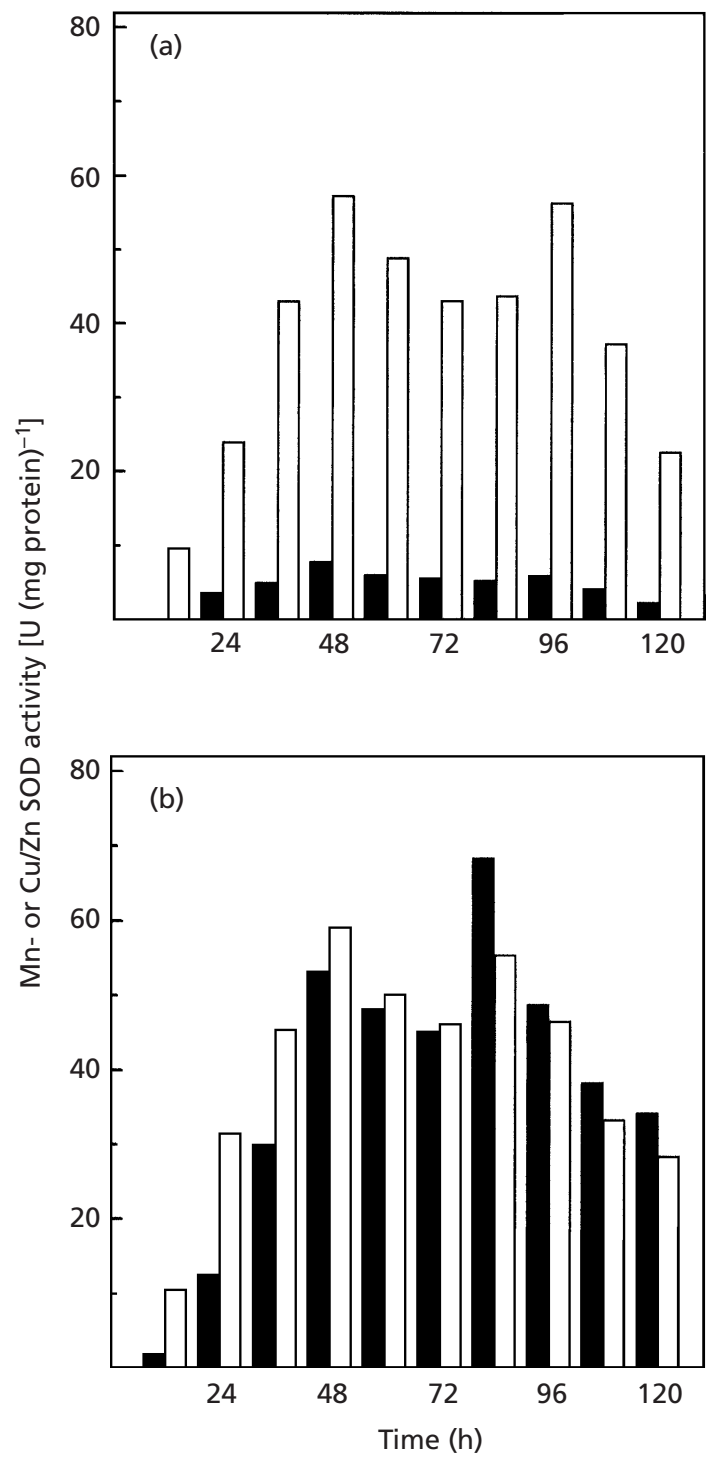

Fig. 2. Isoenzyme profiles of SOD produced by $H$. lutea upon cultivation at different DO levels. (a) Uncontrolled DO; (b) controlled DO (20\%). ם, Mn SOD; $\square$, Cu/Zn SOD.

growth medium (Hassan, 1983). To produce SOD in large quantities, we examined growth, glucose uptake and formation of SOD by H. lutea 103 in a bioreactor under DO-uncontrolled and 20\% DO-controlled conditions (Fig. 1a, b).

Under DO-uncontrolled conditions, the culture showed a typical profile of fungal growth (Fig. 1a). The biomass increased rapidly (exponential phase) when glucose uptake was maximal, without a lag period (Fig. 1b). The culture period from 36 to $84 \mathrm{~h}$ (stationary phase) showed decreased fungal growth and the carbohydrate source was almost exhausted. Moreover, the DO level decreased sharply and oscillated around zero. The sudden drop of oxygen concentration might be attributed to the oxygen required for cell growth and metabolism (Petruccioli et al., 1995). 
Table 1. Comparison of SOD productivity at the activity maxima

\begin{tabular}{|c|c|c|c|c|c|c|c|}
\hline $\begin{array}{l}\text { Cultivation } \\
\text { system* }\end{array}$ & $\begin{array}{c}\text { Cultivation } \\
\text { time }(\mathbf{h})\end{array}$ & $\begin{array}{l}\text { Wet cell } \\
\text { weight } \\
\left(\mathrm{gl}^{-1}\right) \dagger\end{array}$ & $\begin{array}{l}\text { Protein } \\
\text { yield } \\
\left(\mathrm{mg} \mathrm{l}^{-1}\right) \ddagger\end{array}$ & $\begin{array}{l}\text { Specific SOD } \\
\text { activity }[\mathrm{U}(\mathrm{mg} \\
\left.\text { protein })^{-1}\right] \mathbb{S}\end{array}$ & $\begin{array}{c}10^{-3} \times \text { total } \\
\text { SOD activity } \\
\left(\mathrm{U}^{-1}\right) \|\end{array}$ & $\begin{array}{c}10^{-3} \times \text { SOD } \\
\text { productivity } \\
\left(\mathrm{U} \mathrm{kg}^{-1}\right) \mathrm{g}\end{array}$ & $\begin{array}{c}\mathrm{Cu} / \mathrm{Zn} \\
\operatorname{SOD}(\%) \#\end{array}$ \\
\hline \multicolumn{8}{|l|}{ Uncontrolled DO } \\
\hline 1st maximum & 48 & $89 \cdot 67$ & $468 \cdot 75$ & $65 \cdot 39$ & $30 \cdot 7$ & $341 \cdot 8$ & 87 \\
\hline 2nd maximum & 102 & $64 \cdot 25$ & $305 \cdot 40$ & $71 \cdot 34$ & $21 \cdot 8$ & $339 \cdot 0$ & 89 \\
\hline \multicolumn{8}{|c|}{ Controlled DO $(20 \%)$} \\
\hline 1st maximum & 48 & $81 \cdot 24$ & $282 \cdot 30$ & $112 \cdot 09$ & $31 \cdot 6$ & $389 \cdot 5$ & 53 \\
\hline 2nd maximum & 84 & $42 \cdot 56$ & $84 \cdot 42$ & $123 \cdot 61$ & $10 \cdot 4$ & $245 \cdot 1$ & 45 \\
\hline
\end{tabular}

*H. lutea was cultivated under conditions of uncontrolled DO and controlled DO (20\%; see Methods).

† Wet biomass with $75 \%$ humidity.

$\ddagger$ Calculated as mg intracellular protein produced in the wet biomass (litre culture medium) $)^{-1}$.

$\$$ Activities at the time of harvest (see Fig. 1b).

$\|$ Calculated as the amount of enzyme (litre culture medium) $)^{-1}$.

9 Calculated as the amount of enzyme ( $\mathrm{kg}$ wet biomass) ${ }^{-1}$.

\# Expressed as a percentage of total SOD activity using the data from Figs 1(b) and 2.

Irrespective of accelerated glucose uptake (Fig. 1b), $20 \%$ DO-controlled conditions led to a reduction in duration of the stationary phase as well as to a decrease in the maximum level of biomass (Fig. 1a) and intracellular protein content (data not shown). Petruccioli et al. (1995) and Guidot et al. (1993) demonstrated similar data for Penicillium variable and Saccharomyces cerevisiae, respectively, due to increasing DO level.

The effects of two different levels of DO (uncontrolled DO and DO at $20 \%$ ) on SOD production were evaluated (Fig. 1b). Increasing enzyme activity in $H$. lutea cells, cultivated under both conditions, was detected in the early exponential phase and an active synthesis was observed during a period of intensive oxygen consumption. Moreover, the time courses of SOD production show two maxima. A similar phenomenon, a secondary increase in SOD activity during the late stationary phase, has been observed for SOD production by filamentous fungi and yeasts (Shilova et al., 1989; Angelova et al., 1996). It can be explained by an intensification of the process of ${ }^{\cdot} \mathrm{O}_{2}^{-}$generation when the cells utilize endogenous sources of carbon and nitrogen (organic or amino acids).

The results demonstrated that the oxygen level had a significant influence on SOD activity. Under high DO conditions, higher levels of SOD were produced at 1st and 2nd maxima, reaching activities of about 112 and $123 \mathrm{U}$ (mg protein $)^{-1}$, respectively. Considering enzyme formation in both experiments, DO-controlled cultures produce approximately $1 \cdot 7$-fold higher SOD activity than DO-uncontrolled cultures. Exposure to high DO levels has been reported to cause both enhancement (Vercellone et al., 1990) and decrease (Shilova et al., 1989 ) in SOD activity for microbial cells.

The isoenzyme profiles of SOD, produced by H. lutea upon cultivation at different DO levels, are illustrated in Fig. 2. The fungal strain produces two isoforms, namely $\mathrm{Mn}-$ and $\mathrm{Cu} / \mathrm{Zn}$-containing SOD. $\mathrm{Cu} / \mathrm{Zn}$ SOD activity was obtained as total activity minus the activity in the presence of $2 \mathrm{mM}$ cyanide, and the conclusion from these results is that this isoenzyme was responsible for approximately $90 \%$ of total SOD activity in DOuncontrolled cultures. The numbers of isoforms did not change under hyperoxic conditions when $H$. lutea was exposed to an atmosphere of $20 \% \mathrm{O}_{2}$. There was no significant change in $\mathrm{Cu} / \mathrm{Zn}$ SOD activity, whereas $\mathrm{Mn}$ SOD expression increased 10-12-fold by elevated DO. So, it appears that Mn SOD is the primary defence in $H$. lutea cells against oxygen toxicity. Similar findings about the lack of response of $\mathrm{Cu} / \mathrm{Zn}$ SOD to oxidative stress have been reported for a variety of cells (Stralin \& Marklund, 1994). The dependence of $\mathrm{Cu} / \mathrm{Zn}$ SOD on oxygen was found to be related to the availability of copper to H. lutea (M. Angelova, unpublished data), yeasts (Howlett \& Avery, 1999) and mammalian cells (Roughead et al., 1999).

The results of DO-controlled and DO-uncontrolled SOD production are summarized in Table 1 . The highest efficiency of SOD biosynthesis was achieved at the 1st maximum of activity for both kinds of cultures. Although specific SOD activity was higher at the 2nd maximum, total enzyme activity was only 77 and $33 \%$ of that of the first maximum for DO-uncontrolled and DO-controlled cultures, respectively. Because of the differences in the ratio of isoenzymes, the conditions for achieving the 1 st maximum in DO-uncontrolled cultures appear to be the most appropriate for $\mathrm{Cu} / \mathrm{Zn} \mathrm{SOD}$ production by $H$. lutea 103 . The productivity of $H$. lutea $103 \mathrm{Cu} / \mathrm{Zn}$ SOD is comparable to the maximum enzyme productivity by micro-organisms $\left[300 \times 10^{3} \mathrm{U}\right.$ ( $\mathrm{kg}$ wet biomass) ${ }^{-1}$ ] (Kazanina \& Selezneva, 1992). 
Table 2. Purification steps for Cu/Zn SOD from $H$. lutea 103

\begin{tabular}{|c|c|c|c|c|c|}
\hline Purification step & $\begin{array}{l}\text { Total protein } \\
\qquad(\mathbf{m g})\end{array}$ & $\begin{array}{c}10^{-3} \times \text { total SOD } \\
\text { activity }(\mathrm{U})\end{array}$ & $\begin{array}{l}\text { Specific SOD activity } \\
\qquad\left(\mathbf{U ~ m g}^{-1}\right)\end{array}$ & $\begin{array}{l}\text { Yield } \\
(\%)\end{array}$ & $\begin{array}{l}\text { Purification } \\
\quad \text { (-fold) }\end{array}$ \\
\hline Crude extract (after concentration) & 7089 & 884 & 124 & 100 & $1 \cdot 0$ \\
\hline Acetone fraction $(0 \cdot 4$ vols $)$ & 4343 & 852 & 196 & 96 & $1 \cdot 6$ \\
\hline Acetone fraction $(1 \cdot 1$ vols $)$ & 443 & 329 & 743 & 37 & $6 \cdot 0$ \\
\hline Sephadex G-75 & 100 & 191 & 1894 & 21 & $15 \cdot 2$ \\
\hline DEAE cellulose 52 & 56 & 122 & 2167 & 13 & $17 \cdot 4$ \\
\hline Mono Q 10/10 (FPLC) & 36 & 111 & 3100 & 12 & $25 \cdot 6$ \\
\hline
\end{tabular}

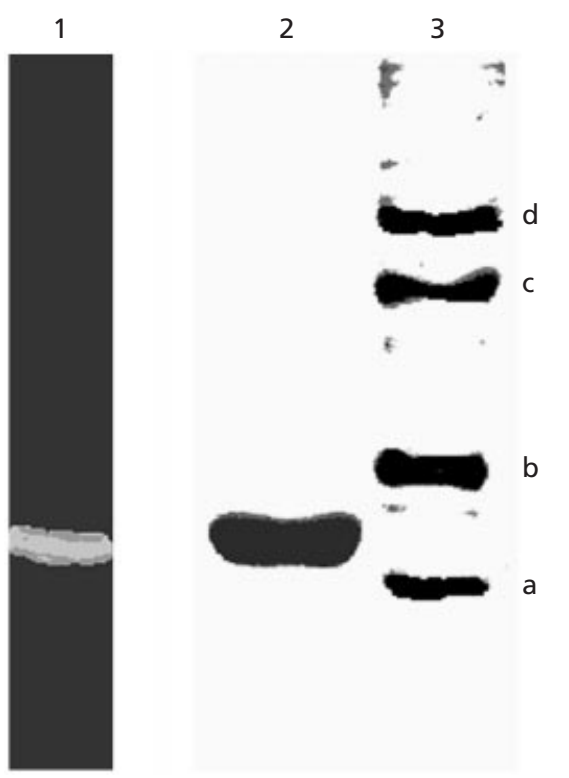

Fig. 3. PAGE (10\% gel) of purified Cu/Zn SOD. Lanes: 1 , gel stained for enzymic activity; 2, gel stained for protein; 3, standard mixture: a, trypsinogen $(24 \mathrm{kDa}) ; \mathrm{b}$, egg albumin (45 kDa); c, bovine albumin (66 kDa); d, Limulus polyphemus haemocyanin (monomer, $70 \mathrm{kDa}$ ).

\section{Purification and characterization of $\boldsymbol{H}$. lutea $\mathrm{Cu} / \mathrm{Zn}$ SOD}

The results of the purification procedure are shown in Table 2. We found that fast-performance anionexchange chromatography (FPLC) on a Mono Q 10/10 column is a highly efficient purification method for $\mathrm{Cu} / \mathrm{Zn}$ SOD. After FPLC purification, the enzyme presents as a single band in PAGE with an activity of $3100 \mathrm{U}$ (mg protein) ${ }^{-1}$ (Fig. 3, lane 1). The presence of 59 ng-atom copper and $52 \mathrm{ng}$-atom zinc (mg enzyme $)^{-1}$ in the purified $H$. lutea $\mathrm{Cu} / \mathrm{Zn} S O D$ was confirmed by atomic absorption spectrometry. No manganese or iron could be detected.

The molecular mass of $H$. lutea $\mathrm{Cu} / \mathrm{Zn} \mathrm{SOD}$ was determined by several methods. The sample was subjected to $12 \%$ SDS-PAGE, producing one band at $32 \mathrm{kDa}$ (Fig. 3, lane 2). The same results were confirmed by means of matrix-assisted laser desorption ionization
MS (Fig. 4.). The mass was calculated to be $31690 \mathrm{Da}$ for the whole molecule and $15845 \mathrm{Da}$ for the structural subunits. From these results it is suggested that the investigated enzyme is a dimer, composed of two identical structural subunits.

The H. lutea $\mathrm{Cu} / \mathrm{Zn} \mathrm{SOD}$ is a glycosylated enzyme, as determined by the orcinol-sulphuric acid assay, with a carbohydrate-binding site, Asn-Xxx-Ser/Thr, typical for N-glycosylation (Francois et al., 1962).

The $\mathrm{N}$-terminal sequence of $\mathrm{Cu} / \mathrm{Zn}$ SOD from $H$. lutea 103 was compared with corresponding regions of $\mathrm{Cu} / \mathrm{Zn}$ SODs isolated from other organisms (Bordo et al., 1994; Forest et al., 2000; Fig. 5). The first 35 residues showed more or less the same percentage $(42-71 \%)$ of identity with the enzymes from eukaryotes. The highest homology was established with the $\mathrm{Cu} / \mathrm{Zn}$ SODs from fungi and yeasts $(71.4$ and $62.9 \%$ with Neurospora crassa and Saccharomyces cerevisiae, respectively). Comparison with enzymes from higher eukaryotes reveals a level of homology of about $48.5 \%$ with human and $42.4 \%$ with bovine $\mathrm{Cu} / \mathrm{Zn}$ SOD. As already mentioned, the enzyme from $H$. lutea 103 shows a low level of homology (about 20\%) with SODs from prokaryotic organisms such as Actinobacillus pleuropneumoniae, Haemophilus ducreyi, Haemophilus influenzae and Haemophilus parainfluenzae.

\section{Effect of $H$. lutea Cu/Zn SOD on the survival of hamsters with transplanted myeloid tumours}

During recent years, clinical investigations have indicated that the oxidant/antioxidant balance is variable during the oncogenic process (Kahlos et al., 1999). Several authors have demonstrated that antioxidant levels in most human and animal cancers are low (Ambrosone et al., 1999). These literature data suggest a new concept for cancer prevention and treatment by systematic modulation of the antioxidant defence system. Moreover, modern cancer therapy produces substantial acute and chronic toxicity that impairs quality of life and limits the effectiveness of treatment (Trotti, 1997). One of the goals of the present experiments was to determine whether inoculation of $H$. lutea SOD would be of therapeutic benefit for hamsters with myeloid Graffi tumour.

The results of the latent time of tumour appearance and 


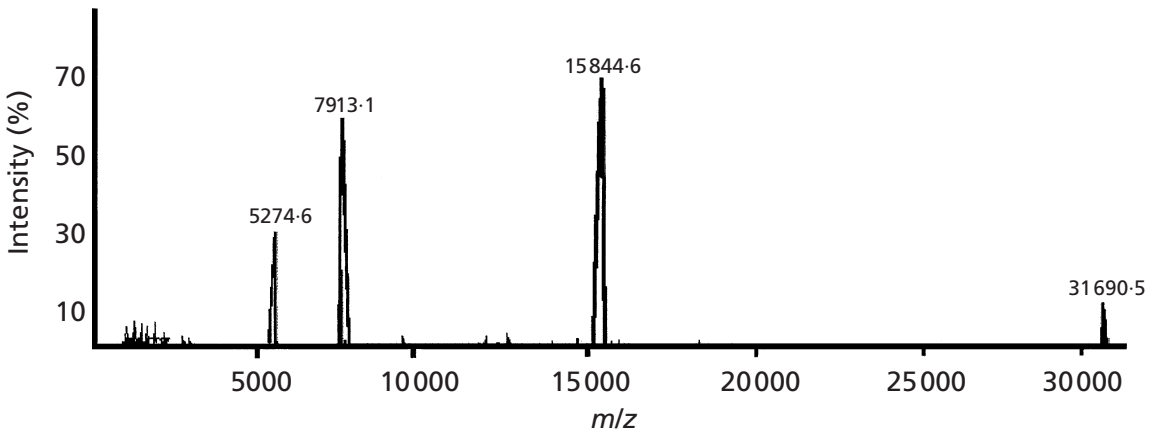

Fig. 4. Matrix-assisted laser desorption ionization mass spectrum of the functional unit of $\mathrm{Cu} / \mathrm{Zn}$ SOD. The sample $(10 \mathrm{pmol})$ was dissolved in $0.1 \%$ TFA and applied onto the target. Analysis was carried out in $\alpha$-cyano-4-hydroxycinnamic acid. Solutions of chicken egg ovalbumin (44400 Da) and bovine serum albumin $(66430 \mathrm{Da})$ were used to calibrate the mass scale.

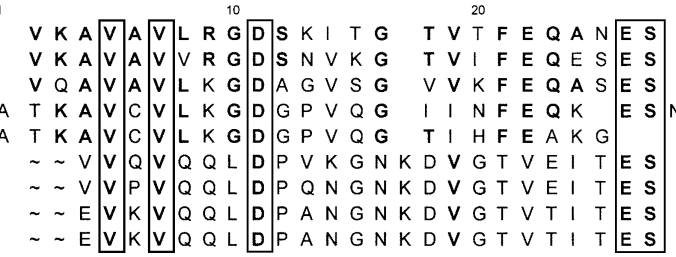

30

A P T T V S WN I T

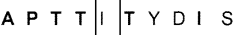

E P T T $V$ V S Y E I A

G P V KVVWGS I T

D T V V V V T G S I T

A Y G L V F T P H L

A Y G L V F F T P K L

N Y G L V V F T P N N

N Y G L V F T P N L
Fig. 5. N-terminal amino acid sequence alignment of $H$. lutea $(H$. I.) Cu/Zn SOD and $\mathrm{Cu} / \mathrm{Zn}$ SODs from eukaryotic and prokaryotic organisms. SOD amino acid sequences are taken from the following sources: human $(H)$, bovine (B), Neurospora crassa (N.C.), Saccharomyces cerevisiae (S. C.) (Bordo et al., 1994), Actinobacillus pleuropneumoniae (A. p.), Haemophilus ducreyi (H.d.), Haemophilus influenzae (H.i.) and Haemophilus parainfluenzae (H.p.) (Forest et al., 2000).
Table 3. Mean latent time for tumour appearance and MST with transplanted myeloid Graffi tumours of hamsters treated i.p. by $\mathrm{H}$. lutea SOD

\begin{tabular}{|lcl|}
\hline Experimental group* & Mean latent time (d) & MST (d) \\
\hline 1 & $10 \cdot 50 \pm 0 \cdot 6$ & $36 \cdot 5 \pm 1 \cdot 5$ \\
2 & $13 \cdot 80 \pm 0 \cdot 8$ & $36 \cdot 0 \pm 1 \cdot 4$ \\
3 & $10 \cdot 75 \pm 0 \cdot 5$ & $39 \cdot 6 \pm 1 \cdot 8$ \\
4 & $10 \cdot 10 \pm 0 \cdot 9$ & $32 \cdot 1 \pm 1 \cdot 2$ \\
\hline
\end{tabular}

*See Methods.

the MST are shown in Table 3. The latent time of tumour appearance was elongated in hamsters of all experimental groups treated with $H$. lutea SOD simultaneously or before tumour transplantation compared to the control group. Furthermore, the application of $H$. lutea SOD enhanced the MST of Graffi-tumour-bearing hamsters. The effect was better expressed in the 3rd group treated with $125 \mathrm{U} \mathrm{H}$. lutea SOD $(39 \cdot 6 \mathrm{~d})$, compared to the untreated control animals $(32 \cdot 1 \mathrm{~d})$. Though groups 1 and 2 were treated with a lower dose of SOD, a comparable value of MST was established (36.5 and $36 \mathrm{~d}$ for groups 1 and 2, respectively).

The results obtained are not surprising because of the scavenging activity of SOD. It has been reported that tumour appearance is accelerated by inflammationinduced active oxygen species, including ${ }^{\circ} \mathrm{O}_{2}^{-}$, and accompanied by decreased levels of intracellular antioxidant enzymes in the cells (Okada et al., 1999; Seidman et al., 1999). Addition of SOD leads to a reduction of
- $\mathrm{O}_{2}^{-}$flux and prevents the cells from phenotype alterations (Okada et al., 1999; Ambrosone et al., 1999). Li et al. (1998) demonstrated a protective effect of several antioxidants on tumour transformation, both in vivo and in vitro. Oberley \& Buettner (1979) have also shown similar results that i.v. or intra-muscular (i.m.) injection of $\mathrm{Cu} / \mathrm{ZnSOD}$ markedly increased the life span of animals carrying Ehrlich ascites tumour cells or Sarcoma 180 tumour cells in solid form. According to these authors and others (Seidman et al., 1999), the effect must be due to ${ }^{\circ} \mathrm{O}_{2}^{-}$-scavenging outside the cell.

On the other hand, it is worthwhile mentioning that groups 2 and 3 show a different response in both determinations (Table 3). Whereas the higher dose (125 U; 3rd group) caused the highest value of MTS, the lower dose (65 U; 2nd group) was more suitable for the prevention of tumour appearance. These data suggest that the effect of exogenous added H. lutea SOD is stagedependent. In the first stage of carcinogenesis, the levels of antioxidant enzymes (SOD and catalase) in tumourbearing hamsters (TBH) were almost equal with those in the control animals (E. Ivanova, unpublished data) and a single dose of $65 \mathrm{U}$ SOD was sufficient to restore the oxidant/antioxidant balance in the host organism. In contrast, because of the interference of the endogenous SOD with the higher dose of injected $H$. lutea SOD (125 U; 3rd group), a significant increase in $\mathrm{H}_{2} \mathrm{O}_{2}$ accumulation was established (E. Ivanova, unpublished data). Moreover, the treatment of TBH with $H$. lutea SOD caused an insignificant increase in catalase activity in liver and tumour cells (E. Ivanova, unpublished data) and consequently enhances the cell's ability to generate the highly toxic hydroxyl radical (Fenton reaction). 


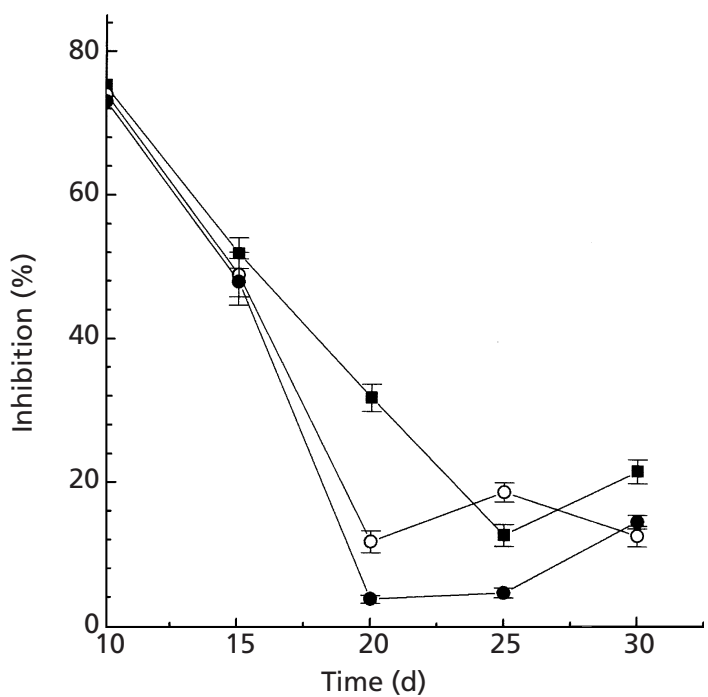

Fig. 6. Inhibition of tumour growth (\%) in Graffi-tumourbearing hamsters treated by $H$. lutea SOD. The values are calculated as the percentage decrease in diameter of tumours of $H$. lutea SOD-treated hamsters [groups $1(\boldsymbol{\square}), 2(O)$ and 3 (O)] relative to the diameter of tumours of hamsters without treatment (group 4). Experimental groups are described in Methods.

Regarding the MST, a possible interpretation of the data includes our previous results obtained during the tumour progression stage: (i) the superoxide production by phagocytes was four- to fivefold higher in $\mathrm{TBH}$ compared to the control animals (Dimitrova et al., 2000); (ii) the levels of SOD and catalase decreased in TBH compared to the healthy animals (E. Ivanova, unpublished data). Probably, this modification of the antioxidant defence during tumour growth resulted in a serious disturbance of the oxidant/antioxidant balance in the cells. It is possible that the higher dose of injected $H$. lutea SOD (125 U) restores the redox balance to a higher degree compared to the dose of $65 \mathrm{U}$.

The H. lutea SOD treatment furthermore inhibited tumour growth in the early stage of tumour progression $(73-75 \%$ at day 10 and $48-50 \%$ at day 15 for the experimental animals in groups $1-3$; Fig. 6). During the following days the most expressed inhibition of tumour growth was established for group 1. It has been reported that reduction of the radicals and oxidants with antioxidants, including SOD, antagonizes tumour promotion activity (Kong \& Lillehei, 1998). Our results supported this concept that SOD has a protective effect during the promotional phases of cancer development (Matès \& Sánchez-Jimenez, 2000).

\section{Protective effect of the $\boldsymbol{H}$. lutea SOD in murine experimental influenza virus infection}

Because recently available vaccines are not completely protective against influenza virus infection and no specific therapy of proven value currently exists for

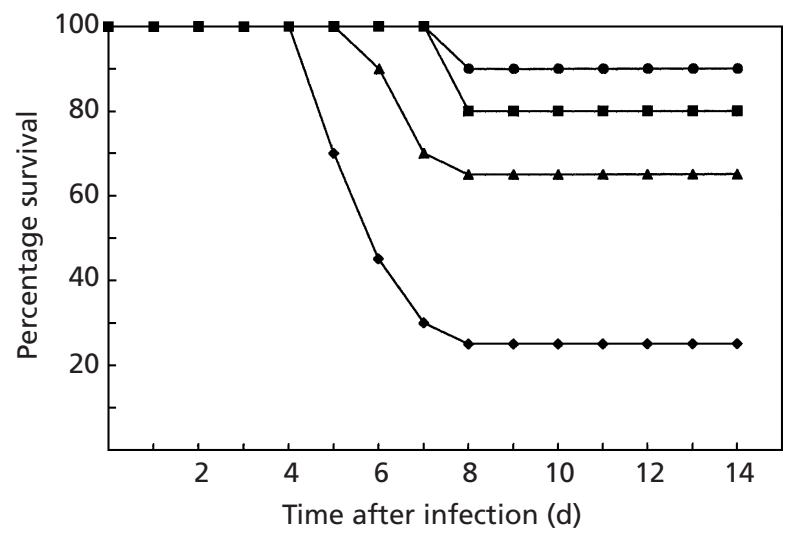

Fig. 7. Protective effect of fungal $\mathrm{Cu} / \mathrm{Zn}$ SOD on experimental influenza infection with A/Aichi (H3N2) in mice. $\diamond$, Virus control; fungal SOD $\left(4 \times 500 \mathrm{U}\right.$ per mouse $\mathrm{d}^{-1}$, i.v. $)$; $\mathbf{A}$, bovine SOD $\left(4 \times 500 \mathrm{U}\right.$ per mouse $\mathrm{d}^{-1}$, i.v. $)$; $\boldsymbol{口}^{\text {, ribavirin }}$ $\left(4 \times 125 \mathrm{mg}\right.$ per mouse $\mathrm{d}^{-1}$, i.p.). Inoculations were performed on days 4-7 each after viral exposure (day 0 ). Values were taken from 10 animal experiments for each group.

severe forms of the infection, there is great interest in the development of new strategies for its control.

The preliminary results from toxicity studies showed that the fungal SOD did not cause either acute or chronic toxicity in experimental animals, treated fourfold with doses of $500 \mathrm{U}$ per mouse $\mathrm{d}^{-1}$. It is significant that no cytotoxicity was observed in cell culture studies (results not shown).

The design of the treatment was evaluated after a series of preliminary experiments. We found that the optimal schedule for treatment included four consecutive i.v. inoculations of $500 \mathrm{U}$ per mouse $\mathrm{d}^{-1}$ on days 4-7 after viral exposure that caused $80 \%$ mortality in the control group. The protective effect of SOD treatment during the critical period of influenza-induced pneumonitis on the survival of mice is presented in Fig. 7. Our results indicate that treatment with $H$. lutea SOD exhibits a strong protective effect on experimental influenza virus infection in mice and that this effect occurs, if the virus challenge is moderate and when the therapy is initiated late during infection. The lateness of therapy initiation particularly relates well to the time when one would anticipate starting therapy in the human patient. The survival rate increases markedly with respect to placebo control: the time of survival rises within $5 \cdot 2 \mathrm{~d}$ and the protective index reaches $86.1 \%$. The effect of the fungal SOD is comparable to that of the selective antiviral drug ribavirin. Bovine SOD at a dose of $500 \mathrm{U}_{\text {per mouse } \mathrm{d}^{-1}}$ also protects mice from mortality significantly, though less efficiently. The higher efficiency of $H$. lutea SOD could be explained by the presence of a carbohydrate chain attached to the glycosylation site of the fungal enzyme. Human, bovine and recombinant $\mathrm{Cu} / \mathrm{Zn}$ SOD are metalloproteins lacking oligosaccharides. For all of these a protective effect against influenza infection has been reported which is, however, less than that with the 
fungal $H$. lutea SOD glycoprotein. Human SOD, inoculated at a dose of $1000 \mathrm{U}$ per mouse at a late stage of infection caused $60-80 \%$ survival (Dolganova \& Sharonov, 1997; Sharonov et al., 1991), bovine $\mathrm{Cu} / \mathrm{Zn}$ SOD at a dose of $1000 \mathrm{U}$ per mouse resulted in $60 \%$ survival of the infected mice (Oda et al., 1989) and treatment with recombinant $\mathrm{Cu} / \mathrm{Zn}$ SOD $(1 \mathrm{mg}$ per mouse $\mathrm{d}^{-1}$ ) exhibited low protective activity only (40\% survival) (Nimrod et al., 1994).

Recently, the effect of reactive oxygen species was suggested to play a role in influenza infection pathogenesis (Oda et al., 1989). In murine models, influenzavirus-induced pneumonitis leads to a remarkable increase in intracellular and extracellular oxygen radicals (Akaike et al., 1996). It has been suggested that the main cause of mortality is the cytotoxicity which is determined by the substantially increased levels of ${ }^{\circ} \mathrm{O}_{2}^{-}$ rather than by the viral replication per se in bronchial epithelial cells (Akaike et al., 1996). This hypothesis has been confirmed by the fact that inoculation of the reactive oxygen species scavenger $\mathrm{Cu} / \mathrm{Zn}$ SOD (conjugated with a pyran polymer) reduced the mortality rate dramatically in experimental animals (Oda et al., 1989). Significant improvement of survival in lethal influenza virus infection has been achieved also by the application of native human SOD (Sharonov et al., 1991) and recombinant Mn SOD (Sidwell et al., 1996). The therapeutic effect of SOD seems to be connected with its ability to scavenge ${ }^{\prime} \mathrm{O}_{2}^{-}$radicals which are the main factor in pathological changes (Oda et al., 1989). It is apparent from the lack of in vitro antiviral activity observed after SOD treatment, that the diseaseinhibitory effect of the metalloproteins is not the result of a direct antiviral effect (data not shown; Sidwell et al., 1996).

The results from the present investigations on the protective effect of the novel fungal $\mathrm{Cu} / \mathrm{Zn} S O D$ on experimental influenza infection can be considered as encouraging. They support the findings that the appropriate use of reactive oxygen species scavengers, applied alone or in combination with selective viral inhibitors, is a promising approach for the treatment of influenza virus infection.

\section{ACKNOWLEDGEMENTS}

This work was supported by grant No 973968/1999-2000 from NATO, grant No 436 BUL 113/112/0 from DFG (Deutsche Forschungsgemeinschaft) and grant 5012/98 from the Fund for Structural and Technological Policy of the Ministry of Education and Science, Bulgaria. Furthermore, we thank Fonds der Chemischen Industrie for financial support.

\section{REFERENCES}

Akaike, T., Noguchi, T., ljuri, S., Setoguchi, K., Suga, M., Zheng, Y., Dietzschold, B. \& Maeda, H. (1996). Pathogenesis of influenza virus-induced pneumonia: Involvement of both nitric oxide and oxygen radicals. Proc Natl Acad Sci US A 93, 2448-2453.

Ambrosone, C. B., Freudenheim, J. L., Thomson, P. A. \& 7 other authors (1999). Manganese superoxide dismutase (MnSOD) genetic polymorphisms, dietary antioxidants, and risk of breast cancer. Cancer Res 59, 602-606.

Angelova, M., Genova, L., Slokoska, L. \& Pashova, S. (1995). Effect of glucose on the superoxide dismutase production in fungal strain Humicola lutea. Can J Microbiol 41, 978-983.

Angelova, M., Genova, L., Pashova, S., Slokoska, L. \& Dolashka, P. (1996). Effect of cultural conditions on the synthesis of superoxide dismutase by Humicola lutea 110. J Ferment Bioeng 82, 464-468.

Beauchamp, C. \& Fridovich, I. (1971). Superoxide dismutase: Improved assay and an assay applicable to polyacrylamide gels. Anal Biochem 44, 276-287.

Bordo, D., Djinovíc, K. \& Bolognesi, M. (1994). Conserved patterns in the $\mathrm{Cu}, \mathrm{Zn}$ superoxide dismutase family. J Mol Biol 238, 366-386.

D’Agnillo, F. \& Chang, T. M. (1998). Polychemoglobin-superoxide dismutase-catalase as a blood substitute with antioxidant properties. Nat Biotechnol 16, 667-671.

Dimitrova, P., Toshkova, R., Ivanova, E., Stefanova, Z., Angelova, M., Dolashka, P. \& Voelter, W. (2000). Superoxide production by phagocytes in myeloid Graffi tumour-bearing hamsters. $Z$ Naturforsch 55c, 788-805.

Dolganova, A. \& Sharonov, B. P. (1997). Application of various antioxidants in the treatment of influenza. Braz J Med Biol Res 30, 1333-1336.

Edlund, A., Edlund, T., Hjalmarsson, K., Marklund, S. L., Sandström, J., Strömqvist, M. \& Tibell, L. (1992). A nonglycosylated extracellular superoxide dismutase variant. Biochem J 288, 451-456.

Forest, K. T., Langford, P. R., Kroll, J. S. \& Getzoff, E. D. (2000). $\mathrm{Cu}, \mathrm{Zn}$ Superoxide dismutase structure from a microbial pathogen establishes a class with a conserved dimer interface. J Mol Biol 296, 145-153.

Francois, C., Marshall, R. D. \& Neuberger, A. (1962). Carbohydrates in protein. Biochem J 83, 335-341.

Fridovich, I. (1995). Superoxide radicals and superoxide dismutases. Annu Rev Biochem 64, 97-112.

Fujita, T., Furitsu, H., Nishikawa, M., Takakura, Y., Sezaki, H. \& Hashida, M. (1992). Therapeutic effects of superoxide dismutase derivatives modified with mono- or polysaccharides on hepatic injury induced by ischaemia/reperfusion. Biochem Biophys Res Commun 189, 191-196.

Guidot, D. M., McCord, J. M., Wright, R. M. \& Repine, J. E. (1993). Absence of electron transport $\left(\mathrm{Rho}^{0}\right.$ state) restores growth of a manganese-superoxide dismutase-deficient Saccharomyces cerevisiae in hyperoxia. Evidence for electron transport as a major source of superoxide generation in vivo. J Biol Chem 268, 26699-26703.

Hassan, H. M. (1983). Oxygen toxicity and mutagenicity in prokaryotes. In Oxy Radicals and Their Scavenger Systems. Molecular Aspects, vol 1, pp. 198-206. Edited by G. Cohen \& R. Greenwald. Amsterdam, New York, Oxford: Elsevier.

Howlett, N. G. \& Avery, S. V. (1999). Flow cytometric investigation of heterogeneous copper-sensivity in asynchronously grown Saccharomyces cerevisiae. FEMS Microbiol Lett 176, 379-386.

Kahlos, K., Pitkanen, S., Hassinen, I., Linnainmaa, K. \& Kinnula, V. L. (1999). Generation of reactive oxygen species by human mesothelioma cells. Br J Cancer 80, 25-31.

Kakimoto, K., Kojima, Y., Ishii, K., Onone, K. \& Maeda, H. (1993). The suppressive effect of gelatin-conjugated superoxide dismutase 
on disease development and severity of collagen induced arthritis in mice. Clin Exp Immunol 94, 241-246.

Kazanina, G. A. \& Selezneva, A. A. (1992). Yeast superoxide dismutase: isolation and properties. Prikl Biochim Microbiol 28, 165-172 (in Russian).

Kong, Q. \& Lillehei, K. O. (1998). Antioxidant inhibitors for cancer therapy. Med Hypotheses 51, 405-409.

Laemmli, U. K. (1970). Cleavage of structural proteins during the assembly of the head of bacteriophage T4. Nature 227, 680-685.

Li, J. J., Rhim, J. S., Schlegel, R., Vousden, K. H. \& Colburn, N. H. (1998). Expression of dominant negative Jun inhibits elevated AP-1 and NF-kB transactivation and suppresses anchorage independent growth of HPV immortalized human keratinocytes. Oncogene 16, 2711-2721.

Maksimenko, A. V., Petrov, A. D., Caliceti, P., Konovalova, G. G., Schiavon, O., Grigor'eva, E. L., Lankin, V. Z. \& Veronese, F. M. (1993). The modification of $\mathrm{Cu}, \mathrm{Zn}$-superoxide dismutase by monomethoxypolyethylene glycol improves the indices of the experimental therapy of the ischemic myocardium in rats. Eksp Klin Farmakol 56, 14-18 (in Russian).

Matès, J. M. \& Sánchez-Jimènez, F. (1999). Antioxidant enzymes and their implications in pathophysiologic processes. Front Biosci 4, D339-D345.

Matès, J. M. \& Sánchez-Jimènez, F. (2000). Role of active oxygen species in apoptosis: implications for cancer therapy. Int $J$ Biochem Cell Biol 32, 157-170.

Misra, H. P. \& Fridovich, I. (1977). Purification and properties of superoxide dismutase from red alga, Porphyridium cruentum. $J$ Biol Chem 252, 6421-6423.

Nakauchi, K., Ikata, T., Katoh, S., Hamada, Y., Tsuchiya, K. \& Fukuzawa, K. (1996). Effects of lecithinized superoxide dismutase on rat spinal cord injury. J Neurotrauma 13, 573-582.

Nimrod, A., Ezov, N., Parizada, B., Weiss, L., Tochner, Z., Slavin, S., Panet, A. \& Gorecki, M. (1994). Human recombinant CuZn SOD and $\mathrm{Mn}$ SOD as potential therapeutic agents. In Frontiers of Reactive Oxygen Species in Biology and Medicine V, pp. 383-387. Edited by K. Asada \& T. Yoshikawa. Amsterdam, New York, Oxford: Elsevier.

Oberley, L. W. \& Buettner, G. R. (1979). Role of superoxide dismutase in cancer: A review. Cancer Res 39, 1141-1149.

Oda, T., Akaike, T., Hamamoto, T., Suzuki, F., Hirano, T. \& Maeda, H. (1989). Oxygen radicals in influenza-induced pathogenesis and treatment with pyran polymer-conjugated SOD. Science 244, 974-976.

Okada, F., Nakai, K., Kobayashi, T. \& 15 other authors (1999). Inflammatory cell-mediated tumour progression and minisatellite mutation correlate with the decrease of antioxidative enzymes in murine fibrosarkoma cells. Br J Cancer 79, 377-385.

Petruccioli, M., Fenice, M., Piccioni, P. \& Federici, F. (1995). Effect of stirred speed and buffering agents on the production of glucose oxidase and catalase by Penicillium variable (P16) in benchtop bioreactor. Enzyme Microb Technol 17, 336-339.

Rios, L., Cluzel, J., Vennat, J. C., Menerath, J. M. \& Doly, M. (1999). Comparison of intraocular treatment of DMTU and SOD following retinal ischemia in rats. J Ocul Pharmacol Ther 15, 547-556.

Roughead, Z. K., Johnson, L. K. \& Hunt, J. R. (1999). Dietary copper primarily affects antioxidant capacity and dietary iron mainly affects iron status in a surface response study of female rats fed varying concentrations of iron, zinc and copper. $J$ Nutr 129, 1368-1376.

Sabitha, K. E. \& Shyamaladevi, C. S. (1999). Oxidant and antioxidant activity changes in patients with oral cancer and treated with radiotherapy. Oral Oncol 35, 273-277.

Sakajo, S., Minagawa, N. \& Yoshimoto, A. (1993). Characterisation of the alternative oxidase protein in the yeast Hansenula anomala. FEBS Lett 318, 310-312.

Seidman, M. D., Quirk, W. S. \& Shirwany, N. A. (1999). Reactive oxygen metabolites, antioxidants and head and neck cancer. Head Neck 21, 467-479.

Serkedjieva, J. \& Ivanova, E. (1997). Combined protective effect of an immunostimulatory bacterial preparation and rimantadine hydrochloride in experimental influenza A virus infection. Acta Virol 41, 65-70.

Sharonov, B. P., Dolganova, A. V. \& Kisselev, O. I. (1991). The effective use of superoxide dismutase from human erythrocytes in the late stages of experimental influenza infection. Vopr Virusol 36, 477-480 (in Russian).

Shilova, N. K., Matyashova, R. N. \& Ilchenko, A. P. (1989). The effect of aeration on the activity of alcohol oxidase and enzymes utilising hydrogen peroxide in the course of Candida maltosa growth on paraffin. Microbiology (English translation of Microbiologiya) 58, 430-435.

Sidwell, R. W., Huffman, J. H., Bailey, K. W., Wong, M. H., Nimrod, A. \& Panet, A. (1996). Inhibitory effects of recombinant manganese superoxide dismutase on influenza virus infection in mice. Antimicrob Agents Chemother 40, 2626-2631.

Somogyi, M. (1952). Notes on sugar determination. J Biol Chem 195, 19-23.

Stenlund, P. \& Tibell, L. A. (1999). Chimeras of human extracellular and intracellular superoxide dismutases. Analysis of structure and function of the individual domains. Protein Eng 12, 319-325.

Stralin, P. \& Marklund, S. L. (1994). Effects of oxidative stress on expression of extracellular superoxide dismutase, $\mathrm{Cu} / \mathrm{Zn}$-superoxide dismutase and $\mathrm{Mn}$-superoxide dismutase in human dermal fibroblasts. Biochem J 298, 347-352.

Toshkova, R. (1995). Immunity and experiments for immunomodulation in hamsters with experimental myeloidtumour primary induced by virus of Graffi. PhD thesis, Sofia, Bulgaria.

Trotti, A. (1997). Toxicity antagonists in cancer therapy. Curr Opin Oncol 9, 569-578.

Vercellone, P. A., Smibert, R. M. \& Krieg, N. R. (1990). Catalase activity in Campylobacter jejuni: comparison of a wild-type strain with a tolerant variant. Can J Microbiol 36, 449-451.

Yakimov, M., Mladenov, Z., Konstantinov, A. \& Yanchev, I. (1979). Transplantable myeloid tumour in hamsters (MTH) induced by Graffi virus. Gen Compar Pathol 6, 24-35.

Yunoki, M., Kawauchi, M., Ukita, N. \& 7 other authors (1997). Effect of lecithinized superoxide dismutase on traumatic brain injury in rats. J Neurotrauma $14,739-746$.

Received 18 September 2000; revised 19 February 2001; accepted 5 March 2001. 